\title{
Design and Manufacture of a Centrifugal Water Pump with a Circular Casing
}

\section{Francis INEGBEDION ${ }^{1 *}$, Chidiebele Nnadike OKONKWO², Joseph Okechukwu NDIFE ${ }^{3}$}

\author{
${ }^{1}$ Department of Production Engineering, University of Benin, Benin City, Nigeria. \\ * Corresponding Author : Email: francis.inegbedion@ uniben.edu - ORCID: 0000-0002-2142-8079
}

${ }^{2}$ Department of Production Engineering, University of Benin, Benin City, Nigeria.

Email: ogenessmayoro@gmail.com - ORCID: 0000-0002-9543-04542

${ }^{3}$ Department of Production Engineering, University of Benin, Benin City, Nigeria.

Email: ndifendife2@gmail.com - ORCID: 0000-0001-9222-99693

$\underline{\text { Article Info: }}$

DOI: $10.22399 /$ ijcesen.907292

Received : 31 March 2021

Accepted : 24 November 2021

Keywords

Circular casing

Local content

Pump

\begin{abstract}
:
A Centrifugal water pump is a machine that imparts mechanical energy to a fluid flowing through it, this allows the fluid to move from one point to another. This paper reports the design, manufacture and testing of a centrifugal water pump having a circular casing. A single stage, end suction centrifugal pump designed and manufactured, using locally sourced materials. This pump finds application in homes, agriculture and industries. It consists of an impeller, shaft, suction, delivery pipes and an electric motor. Experiments performed with this pump shows that it can deliver $0.0045 \mathrm{~m} 3$ of water per second with a pressure head of $34.7 \mathrm{~m}$. A $2.5 \mathrm{~kW}$ electric motor running at a speed of 2900rpm was used to drive the pump.
\end{abstract}

\section{Introduction}

Pumping is the addition of energy to a fluid to move it from one point to another [1]. A pump is a machine that imparts mechanical energy from some external source to a fluid flowing through it, to move it from one point to another [2]. The development of pumps has enabled man to transport and move liquids from one point to another. The centrifugal pump is the type widely used for general services (home, agriculture, industries etc.) because of its simplicity, low cost, high volumetric discharge, uniform flow, quiet operation, adaptability of use with electric motor, turbine or internal combustion engines and low maintenance expense [3].

A centrifugal pump is a machine consisting of a set of rotating vanes enclosed within a housing or casing. The vanes impart energy to a fluid through centrifugal force, which causes the fluid to move. A centrifugal pomp has two main parts: a rotating element, including an impeller and a shaft, and a stationary element, made up of a casing, stuffing box and bearings. Centrifugal pump usage finds application in machine tools, automobile and aeronautic industries [2]. Most of the centrifugal pumps in Nigeria today are of the volute type casing. It is the aim of this paper to design and manufacture a centrifugal pump having a circular casing using locally available materials. A simple design with a circular casing enclosing an impeller was designed. The impeller and casing material were made from cast iron. The entire unit is a mono block pump i.e. it is a direct coupling of the motor to the impeller.

The development of the centrifugal pump dates back to about 3,000 B.C., where the Mesopotamians used buckets alone to water their crops in the Nile River valley. This later gave way to the waterwheel around 500 B.C. French inventor Dewis Papin invented the centrifugal pump in the late 1600s. His impeller had straight vanes, whereas that developed by the British inventor John G. Appold, in 1851 had the curved vanes still preferred today.

Pumps finds application in automobiles and in the refinery, loading and unloading of tankers, direct handling of boiler feed water, water treatment chemicals, condensate, cooling water etc. The development of pumps has enhanced the level of man civilization, economic, conducive environment and has led to the technological development of modern industries. There is the need to develop, 
design and construct pumps using locally available materials [4].

The significant considerations in the selection of materials for construction of the centrifugal pump included, local availability, low cost, easy handling during fabrication, lightness of weight for easy handling during use, weather ability and long service life (ability to withstand environmental and operating conditions) and non-toxic effects [5].

\section{Methodology}

\subsection{Nomenclature}

\section{$\mathrm{Mmm}$}

$\mathrm{Q}=$ Capacity $(\mathrm{m} 3 / \mathrm{s})$

$\mathrm{H}=$ Head $(\mathrm{m})$

$\mathrm{N}=$ Rotational Speed (rpm)

Ns $=$ Shape Number $(\mathrm{m} / \mathrm{s})$

Nusf $=$ Useful Power $(\mathrm{kW})$

$\rho=$ Density $(\mathrm{kg} / \mathrm{m} 3)$

$\mathrm{Nmp}=$ Motor Power $(\mathrm{kW})$

$\eta=$ Efficiency

D1 = Impeller eye diameter $(\mathrm{mm})$

D2 = Impeller outer diameter $(\mathrm{mm})$

D3 = Casing inside diameter $(\mathrm{mm})$

D4 = Casing outer diameter $(\mathrm{mm})$

b1 $=$ Impeller eye width $(\mathrm{mm})$

b2 = Impeller outer width (mm)

b3 = Casing width $(\mathrm{mm})$

$\mathrm{Tc}=$ Casing thickness $(\mathrm{mm})$

$\varnothing=$ Speed Ratio

$\mathrm{U} 2=$ Impeller rim velocity $(\mathrm{m} / \mathrm{s})$

$\mathrm{U} 1=$ Impeller inner velocity $(\mathrm{m} / \mathrm{s})$

$\eta \mathrm{h}=$ Hydraulic Efficiency

$\mathrm{Vn}=$ True Whirl velocity component $(\mathrm{m} / \mathrm{s})$

$\mathrm{Z}=$ Number of blades

$\mathrm{V} \infty=$ Ideal whirl velocity component $(\mathrm{m} / \mathrm{s})$

$\mathrm{Kn}=$ Factor ranging from $3-5$

$\psi=$ Flow ratio

$\mathrm{Y} 2=$ Velocity of flow $(\mathrm{m} / \mathrm{s})$

$\mathrm{Y} 1=$ Inlet flow velocity $(\mathrm{m} / \mathrm{s})$

$\gamma=$ Outlet blade angle (deg)

$\beta=$ Inlet blade angle (deg)

\subsection{Design of the Centrifugal Pump}

The design data required for the design of the centrifugal pump are as follows:

Flow rate, Q $0.0045 \mathrm{~m}^{3} / \mathrm{s}$

Head, $\mathrm{H}=34.7 \mathrm{~m}$

Pump Speed, N = 2900rpm
Gravitational acceleration, $\mathrm{g}=9.81 \mathrm{~m} / \mathrm{s}^{2}$

Density of water, $\rho=1000 \mathrm{~kg} / \mathrm{m}^{3}$

$$
\begin{aligned}
& K_{s}=3.65 \\
& \varnothing=0.97 \\
& \delta=0.07 \\
& D=35.5
\end{aligned}
$$

$P=50 \mathrm{~m}$ of water

$X=4.5$

$Y=1.6$

$$
Z=6
$$

$d t=2.5$

$$
\begin{aligned}
& N_{S}=K_{S} N\left(\frac{\sqrt{Q}}{H^{\frac{3}{4}}}\right)=47.06 \mathrm{~m} / \mathrm{s} \\
& N_{u s f}=\frac{Q \rho g H}{1000}=1.962 \mathrm{~kW} \\
& N_{m p}=2.5 \mathrm{~kW} \\
& \eta=\frac{N_{u s f}}{N_{m p}}=0.7848
\end{aligned}
$$

\subsection{Impeller Design}

$$
\begin{gathered}
U_{2}=\emptyset \sqrt{2 \mathrm{gH}}=27.174 \mathrm{~m} / \mathrm{s} \\
D_{2}=\frac{60 U_{2}}{\pi N}=0.178959 \mathrm{~m}=178.959 \mathrm{~mm} \\
D_{1}=0.3 D_{2}=53.688 \mathrm{~mm} \\
U_{1}=\frac{\pi D_{1} N}{60} 8.152 \mathrm{~m} / \mathrm{s} \\
b_{1}=\frac{1.5 D_{1}}{4}=0.020133 \mathrm{~m}=20.133 \mathrm{~mm} \\
b_{2}=\frac{b_{1} D_{1}}{D_{2}}=0.006034 \mathrm{~m}=6.034 \mathrm{~mm}
\end{gathered}
$$

\section{$2.4 \quad$ Impeller Blade Angles}

This paragraph deals only with blades suited for two dimensional flows, they are described as cylindrical because they form part of surfaces. The routine calculation proceeds thus:

$$
\begin{aligned}
& \eta_{h}=1-\left\{K_{h}(1-\eta)\right\}=0.8924 \\
& V_{n}=\frac{g H}{\eta_{h} U_{2}}=0.1681 \mathrm{~m} / \mathrm{s} \\
& V_{\infty}=V_{n}\left\{1+\left(K_{n} / Z\right)\right\}=0.2522 \mathrm{~m} / \mathrm{s} \\
& Y_{2}=\psi \sqrt{2 g H}=7.844 \mathrm{~m} / \mathrm{s} \\
& \gamma=\tan ^{-1}\left(\frac{Y_{2}}{U_{2}-V_{\infty}}\right)=16.244^{0} \\
& Y_{1}=Y_{2}\left(\frac{D_{2} b_{2}}{D_{1} b_{1}}\right) 7.836 \mathrm{~m} / \mathrm{s} \\
& \beta=\tan ^{-1} \frac{Y_{1}}{U_{1}}=43.87^{0}
\end{aligned}
$$

Check for exact number of blades, $\mathrm{Z}$

$$
\begin{aligned}
& Z=6.5\left(\frac{m+1}{m-1}\right) \sin \left(\frac{\beta+\gamma}{2}\right)=6 \text { blades } \\
& m=\frac{D_{2}}{D_{1}}=3.3333
\end{aligned}
$$

\subsection{Casing Design}

$$
D_{3}=D_{2}(\delta+1)=191.486 \mathrm{~mm}
$$




$$
\begin{aligned}
& b_{3}=1.25 b_{1}=25.17 \mathrm{~mm} \\
& T_{c}=((X Y D P) / 200 d t)+2=4.56 \mathrm{~mm}
\end{aligned}
$$

From tables;

$10 \mathrm{~m}$ of water $=1 \mathrm{~kg} / \mathrm{mm}^{2}$ and $50 \mathrm{~m}$ of water $=50 \mathrm{x}$ $0.1=5 \mathrm{~kg} / \mathrm{mm}^{2}$

$$
D_{4}=2 T_{c}+D_{3}=201.486 \mathrm{~mm}
$$

\section{Results}

\subsection{Testing of the Centrifugal Pump}

During the testing of the centrifugal pump the Head, Capacity and Efficiency of the pump were measured directly while the pump was in operation. The pump tested in the Department of Production Engineering workshop, University of Benin, Benin City, Nigeria was done by empting water filled in measured containers. The time taken to empty each measured quantity was noted against the Head of water pumped. Water rose to a height of $34.7 \mathrm{~m}$ and the discharge recorded was 16,200 litres/hour i.e. 4.5 litres/sec.

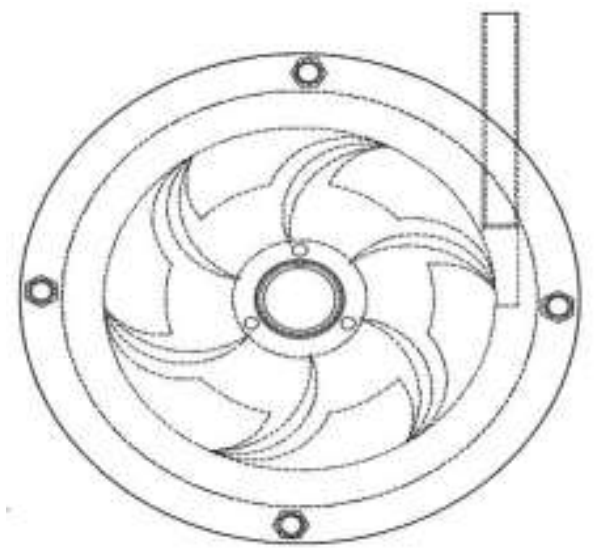

Figure 1: Drawing of the impeller in the circular casing

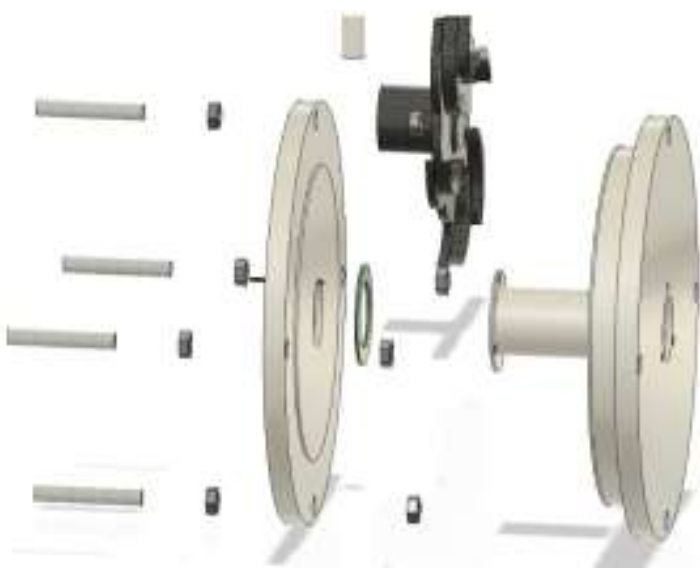

Figure 2: Assembly drawing of the impeller and the circular casing
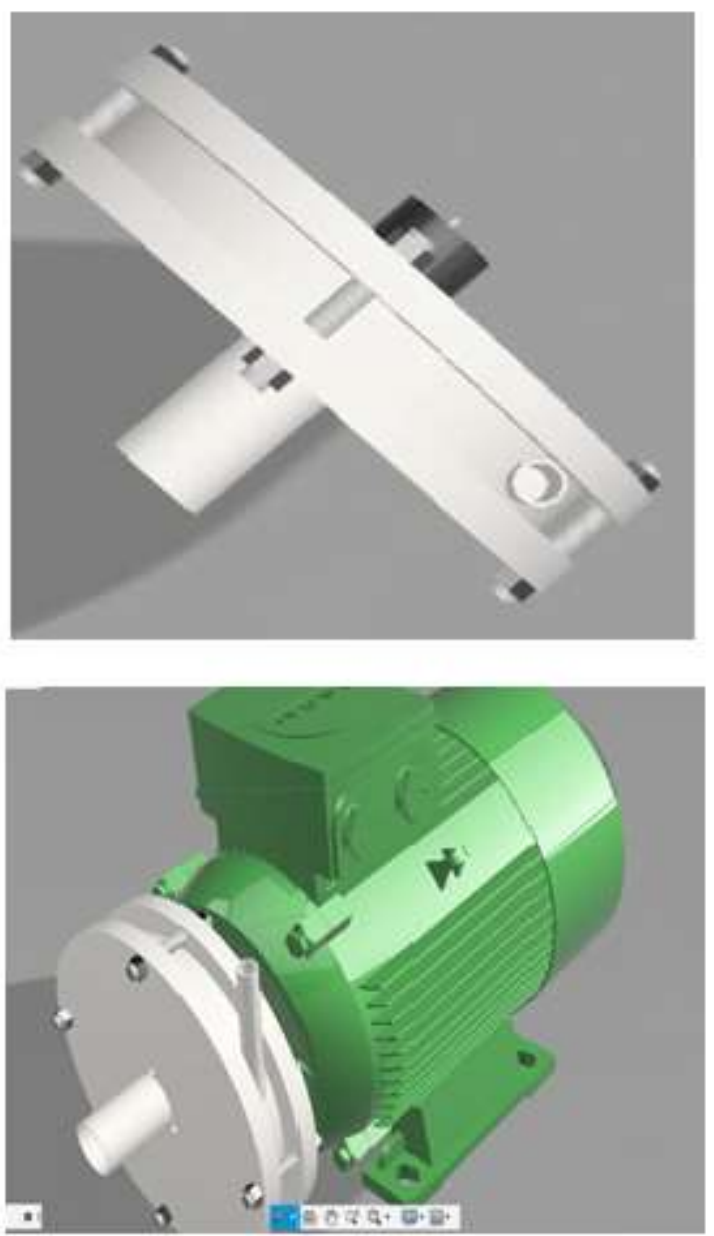

Figure 3. The assembled centrifugal pump with a circular casing

\section{Discussions}

The centrifugal water pump with a circular casing was designed to deliver 5 litres of water per second at a height of $40 \mathrm{~m}$. Therefore, the achieved performance of $90 \%$ efficiency is satisfactory and acceptable for a centrifugal pump that falls within this category of specific speed.

\section{Conclusions}

In the work we have shown that from the simple principle of operation of a centrifugal pump - a motor rotating an impeller in a round casing - water can be raised to an appreciable height. This is evident from the test results obtained. A Head of $34.7 \mathrm{~m}$ and a volume flow rate of 16,200 litres / hour prove very satisfactory. This pump was manufactured using locally sourced materials and fabricated in the Department of Production Engineering workshop. This work will no doubt enhance the technological base of the nation and create jobs if harnessed. 


\section{Author Statements:}

- The authors declare that they have equal right on this paper.

- The authors declare that they have no known competing financial interests or personal relationships that could have appeared to influence the work reported in this paper

- The authors declare that they have nobody or no-company to acknowledge.

\section{References}

[1] Karassik Igor J. and Carter Ray (1960). Centrifugal Pumps Selection, Operation and Maintenance. McGraw - Hill Book Company.

[2] Anderson, H. H. (1957). Centrifugal Pumps. The trade and Technical Press Ltd, England

[3] Okokowa L. E. (2003). A project on the Design and Construction of a 2-Stage Centrifugal Pump, submitted to the Department of Mechanical Engineering, Ambrose Ali University, Ekpoma.

[4]Ozora P.A., Ojoborb S.N., (2012). Design, Construction And Measured Performance Of A Single-Stage Centrifugal Pump Demonstration Unit Nigerian Journal Of Technology Vol. 31, No. 3

[5]Douglas, J.F., Gasiorek, J.M. and Swaffield, J.A. (2001). Fluid Mechanics. 4th edition, Pearson Education. 